\title{
THEORETICAL ANALYSIS OF GAS TURBINE BLADE BY FINITE ELEMENT METHOD
}

\author{
B. Deepanraj*, P. Lawrence** and G. Sankaranarayanan*** \\ *Department of Mechanical Engineering, Adhiparasakthi Engineering College, Melmaruvathur, TN, India. \\ **Department of Mechanical Engineering, Priyadarshini Engineering College, Vaniyambadi, TN, India. \\ ***Department of Mechanical Engineering, Sri Muthukumaran Institute of Technology, Chennai, TN, India.
}

\begin{abstract}
Gas turbine is an important functional part of many applications. Cooling of blades has been a major concern since they are in a high temperature environment. Various techniques have been proposed for the cooling of blades and one such technique is to have axial holes along the blade span. Finite element analysis is used to analyze thermal and structural performance due to the loading condition, with material properties of Titanium- Aluminum Alloy. Six different models with different number of holes $(7,8,9,10,11$, and 12) were analyzed in this paper to find out the optimum number of holes for good performance. In Finite element analysis, first thermal analysis followed by structural analysis is carried out. Graphs are plotted for temperature distribution for existing design (12 holes) and for 8 holes against time. 2D and 3D model of the blade with cooling passages are shown. Using ANSYS, bending stress, deflection, temperature distribution for number of holes are analyzed. It is found that when the numbers of holes are increased in the blade, the temperature distribution falls down. For the blade configuration with 8 holes, the temperature near to the required value i.e., $800^{\circ} \mathrm{C}$ is obtained. Thus a turbine blade with 8 holes configuration is found to be the optimum solution.
\end{abstract}

Keywords: Gas turbine blade; Stress; Deflection; Temperature distribution.

\section{INTRODUCTION}

Gas turbines are used extensively for aircraft propulsion, landbased power generation, and industrial applications. Thermal efficiency and power output of gas turbines increase with increasing turbine rotor inlet temperature. The current rotor inlet temperature level in advanced gas turbines is far above the melting point of the blade material. Therefore, along with high temperature material development, sophisticated cooling scheme must be developed for continuous safe operation of gas turbines with high performance. Gas turbine blades are cooled internally and externally; this paper focuses on turbine blade internal cooling. In this type cooler air is bled from the compressor stage and then passing through internal passages incorporated into blade designs for cooling purpose [1].

\section{METHODS OF COOLING}

\subsection{Internal Cooling:}

Internal cooling of blades can be achieved by passing cooling air from the air compressor through internal cooling passages from hub towards the blade tips. The internal passages may be circular or elliptical and or distributed near the entire surface of blade. The shapes of such blades may deviate from the optimum aero dynamic blade profile. The cooling of the blade is achieved by conduction and convection, relatively hotter air after traversing the entire blade length in the cooling passages escapes to the main flow from the blade tips. Hollow blades can also be manufactured with a core and internal cooling passage. Cooling air enters the leading edge region in the form of a jet and then turns towards the trailing edge $[3,6]$.

\subsection{External Cooling:}

External cooling of the turbine blade is achieved in two ways. The cooling air enters the internal passages from the hub towards the tips. On its way upwards it is allowed to flow the blade surface through a number of small orifices inclined to the surface. The cooling air thus flowing out of these small holes forms a film over the blade surfaces. Besides cooling the blade surface it decreases the heat transfer form hot gases to the blade metal.

\section{FINITE ELEMENT METHOD}

The FEM has become a powerful tool for numerical solution of wide range of engineering problems. The advance in computer technology and high-speed electronic computers

Author for Correspondence: B.Deepanraj, Department of Mechanical Engineering, Adhiparasakthi Engineering College, Melmaruvathur, Tamilnadu, India. Email: babudeepan@gmail.com. 
enables complex problems to model easily. This makes to test in computers before the first prototype is built. In this method of analysis, a complex continuum is defined into simple geometric shapes called FEM. The material properties and governing relationship are considered over these elements and expressed in term of unknown values at elemental corners. An assembly of this simple geometry shapes considering load and constraints, a set of equations are obtained [9].

\section{Steps involved in FEM}

- Select the continuum of the body.

- Selection of the displacement models.

- Derive the stiffness matrix and global load vector.

- Using the force-displacement relationship, the unknown nodal displacements are obtained.

- Using the strain-displacement and stress-strain relationship the unknown values are calculated.

- Faster automatic calculations, which are repetitive in nature, simultaneous display of modifications \& post processing results.

- Accurate prediction with adequate details for identifying critical areas of interest like highly stressed regions.

\section{FINITE ELEMENT ANALYSIS OF GAS TURBINES BLADE}

Finite element analysis can play a vital role by simplifying the analysis. In this work a turbine blade is analyzed for its thermal as well as structural performance due to the loading condition. Six different models having different number of holes were analyzed in this paper to find out the optimum number of holes for good performance.

\section{MODELING OF GAS TURBINE BLADE}

3D model of a turbine blade with hub was done in two stages.

Table 1: Dimensions of the blade

\begin{tabular}{|l|c|}
\hline \multicolumn{1}{|c|}{ Parameter } & Values \\
\hline Blade Span & $120 \mathrm{~mm}$ \\
\hline Blade axial Chord Length & $110 \mathrm{~mm}$ \\
\hline Cooling passage diameter & $2 \mathrm{~mm}$ \\
\hline
\end{tabular}

Table 2: Material properties of Titanium-Aluminium Alloy

\begin{tabular}{|l|c|}
\hline \multicolumn{1}{|c|}{ Strength } & Values \\
\hline Modulus of Elasticity & $118 \mathrm{GPa}$ \\
\hline Poisson's Ratio & 0.3 \\
\hline Yield Stress & $1050 \mathrm{Mpa}$ \\
\hline Coefficient of Thermal Expansion & $7.7 \mathrm{e}^{-6} /{ }^{\circ} \mathrm{c}$ \\
\hline Density & $4507 \mathrm{~kg} / \mathrm{m}^{3}$ \\
\hline Thermal Conductivity & $7 \mathrm{~W} / \mathrm{m} /{ }^{\circ} \mathrm{c}$ \\
\hline Melting Point & $1300^{\circ} \mathrm{c}$ \\
\hline
\end{tabular}

First for creating the 3D model of the turbine blade, key points were created along the profile in the working plane. The points were joined by drawing B Spline curves to obtain a smooth contour. This contour was then converted into area and then volume was generated by extrusion. Then working plane was rotated by $90^{\circ}$ to generate the hub part in the same way as the blade. These two volumes were then combined to make a single volume using union Boolean operation. Holes were then generated along the blade axially by using subtract Boolean operation. The finite element model was created by meshing the 3D model. The turbine blade analyses are unique in a way such that two different element types were involved i.e., thermal and structural analyses respectively. The 3D Solid 87 element was used for meshing during thermal analyses. For structural analyses, Solid 92 element was used.

\section{THERMAL - STRUCTURAL ANALYSIS}

The finite element analysis of the gas turbine blade was done sequentially i.e., thermal analysis was performed first, and then the structural analysis was carried out, by taking into account the results of the thermal analysis. Block diagram of figure 1 explains the above said things.

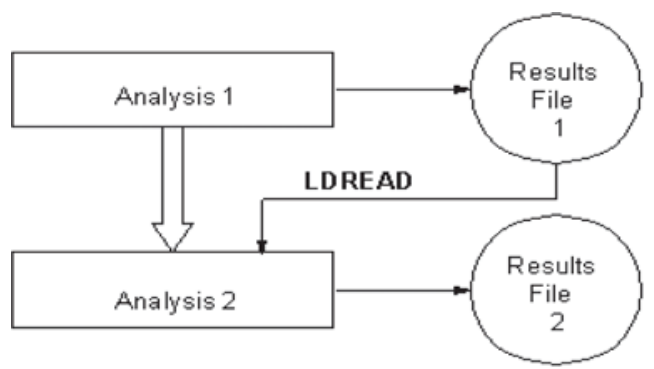

Fig. 1: Block diagram of thermal- structural analysis

\subsection{Thermal analysis}

The transient thermal analysis was performed by applying the loading condition by using a time curve. For this, hot gas temperature was specified along the pressure side of the blade and the cool-ant temperature was applied on the cooling hole surface area. The hub being fixed to the rotor disc, it is constrained in all six degrees of freedom. Different thermal loads and convection boundary conditions were applied on pressure side of the blade model.

\subsection{Structural analysis}

For structural analysis, the model was re-meshed using Solid 92 elements. The pressure load was applied on the pressure side of the blade and the analysis was performed. Since hub side of the blade was fixed with disc, hub side of the blade was fully arrested. Then structural loads were applied on pressure side of the blade model.

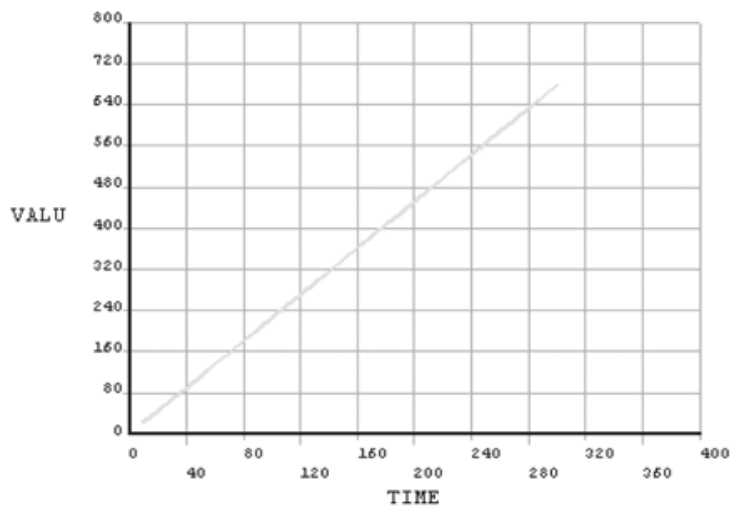

Fig. 2: Temperature Vs time for existing design (12 holes) 


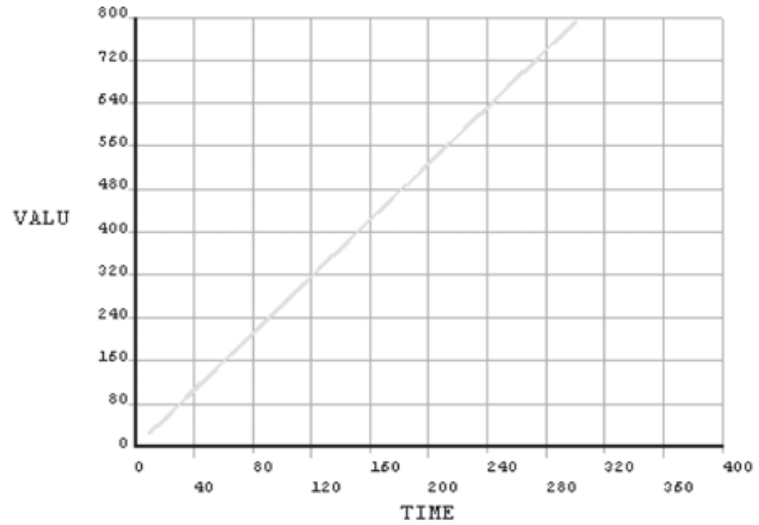

Fig. 3: Temperature Vs time for optimized design (8 holes)

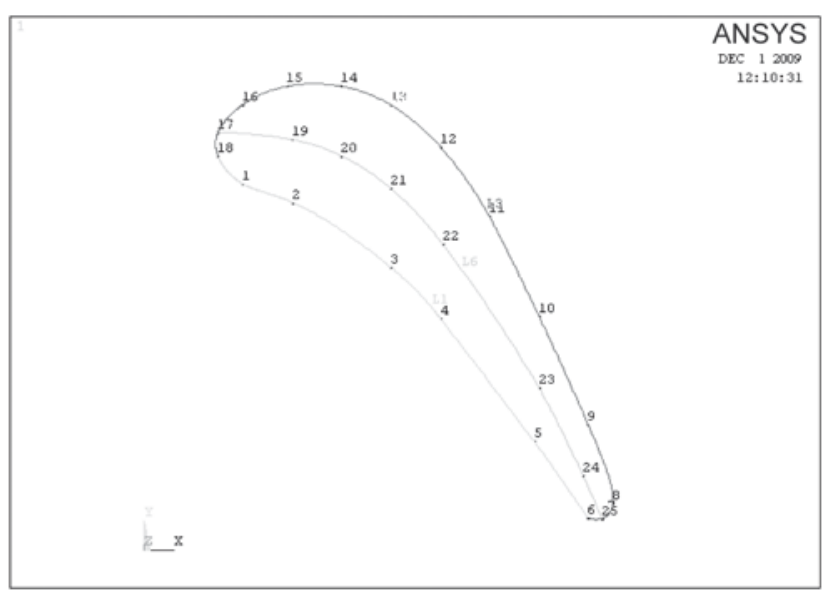

Fig. 4: Key points and splines of the blade

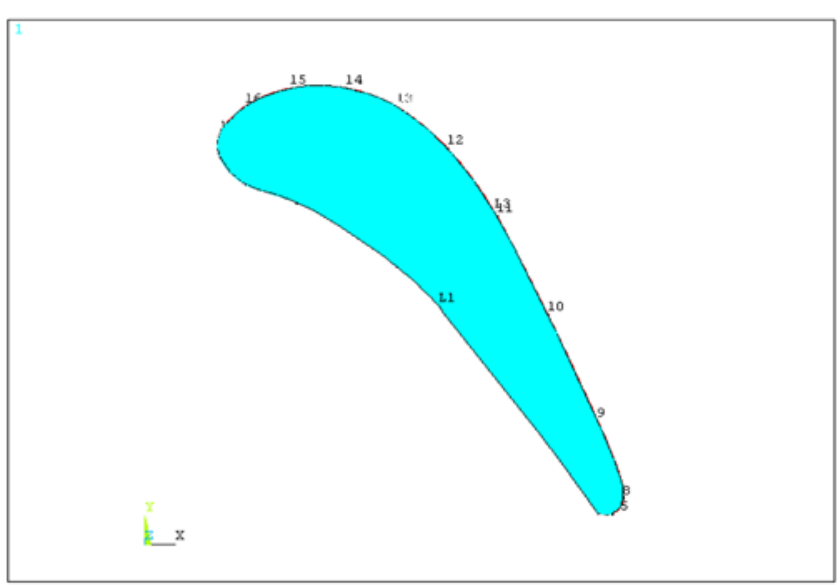

Fig. 5: Two dimensional model of the blade

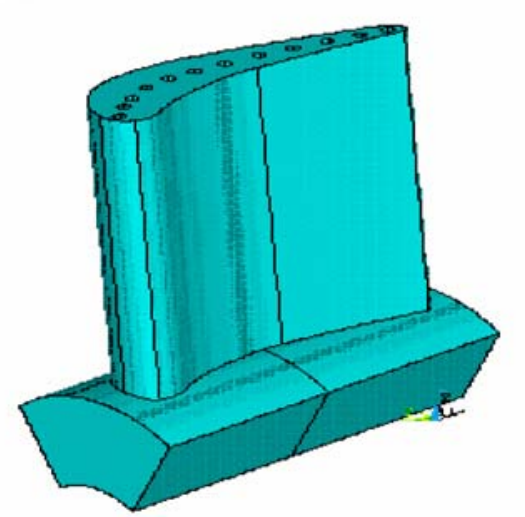

Fig. 6: 3D model of the blade with cooling passages

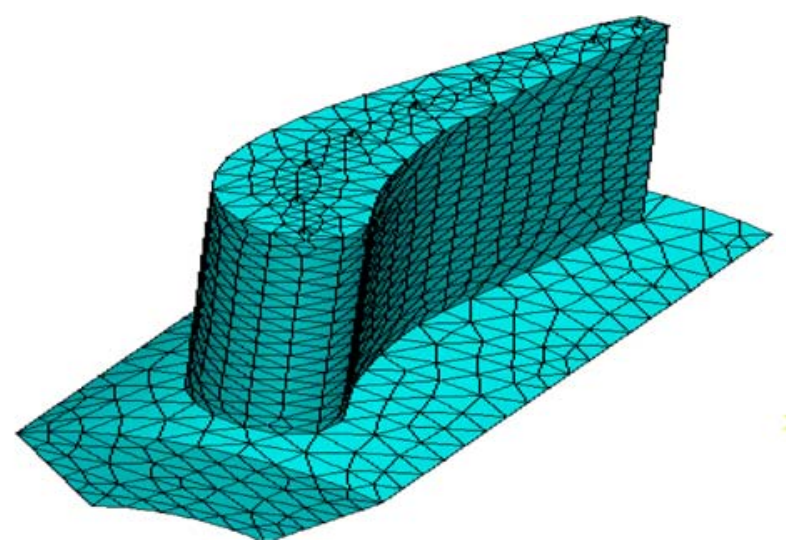

Fig. 7: Finite element model of the blade

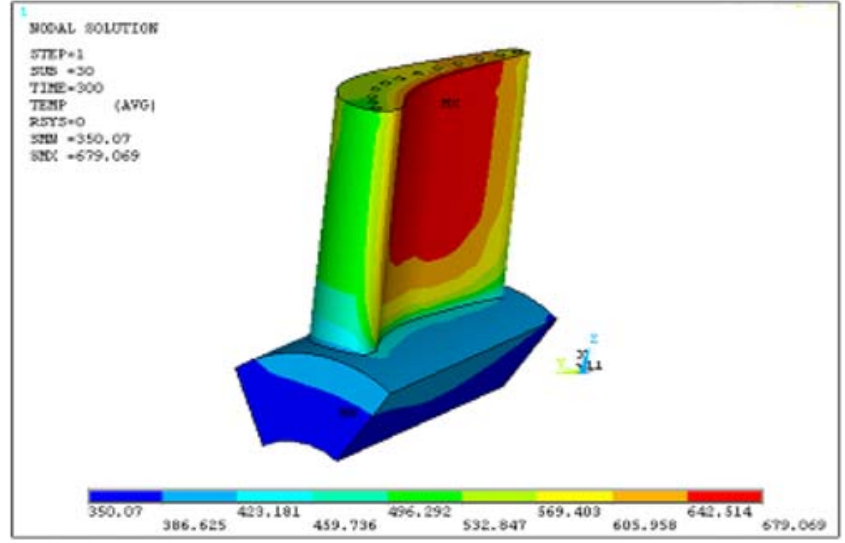

Fig. 8: Temperature distribution for existing design (12 holes)

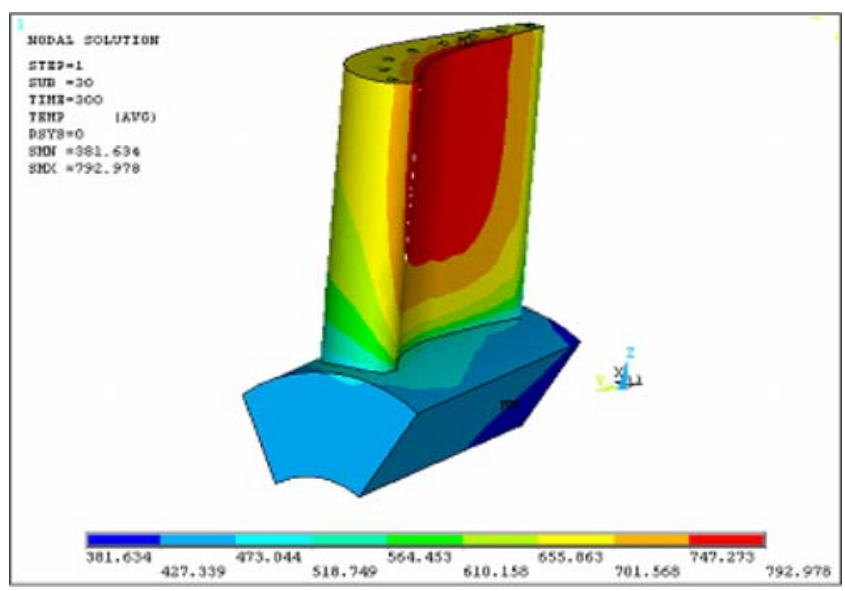

Fig. 9: Temperature distribution for optimized design (8 holes)

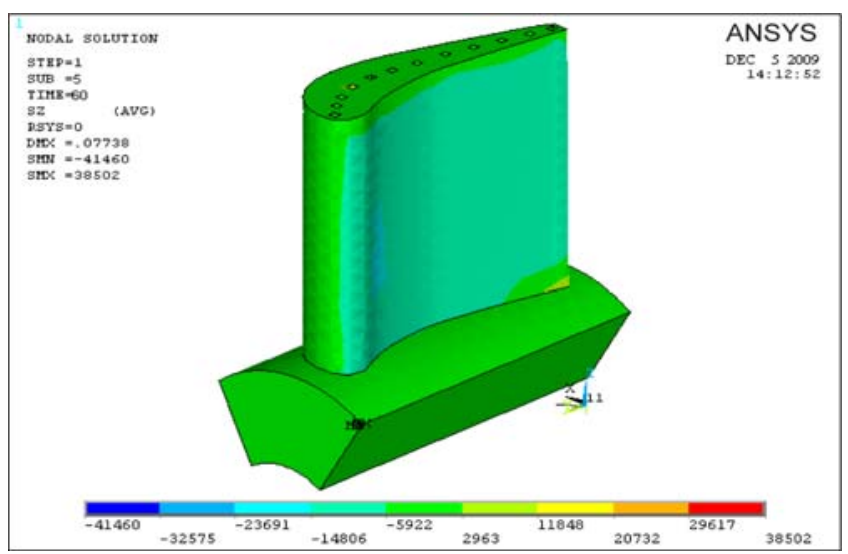

Fig. 10: Stress distribution for existing design (12 holes) 


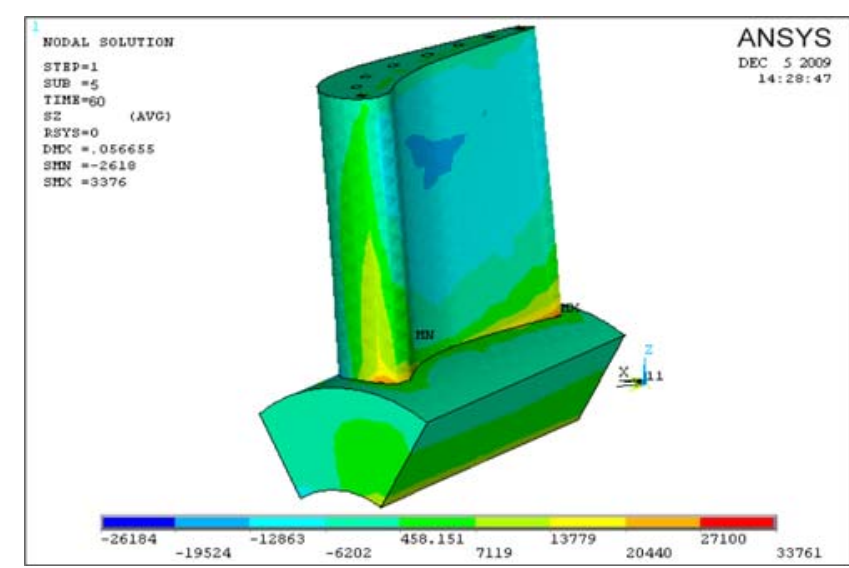

Fig. 11: Stress distribution for optimized design (8 holes)

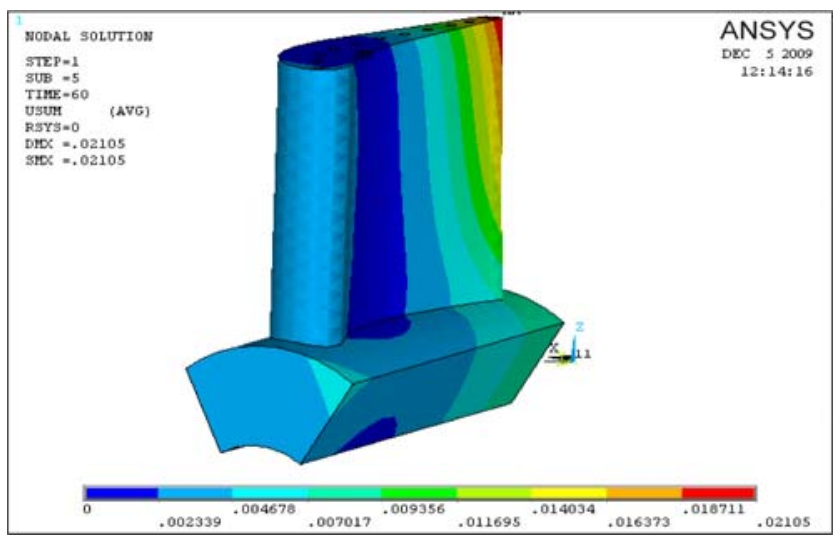

Fig. 12: Deflection plot for existing design (12 holes)

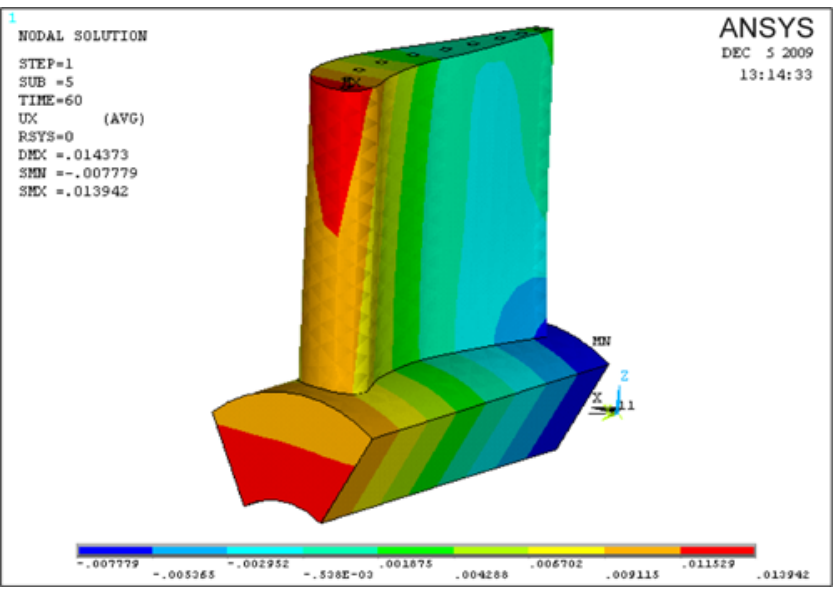

Fig. 13: Deflection plot for optimized design (8 holes)

\section{RESULTS AND DISCUSSIONS}

The thermal-structural finite element analysis was performed for the turbine blade with different number of holes i.e., $12,11,10,9,8,7$ number of holes by specifying thermal and structural loads with an objective of finding optimum number of holes for the best performance. First the existing blade design with 12 holes was analyzed by specifying $500^{\circ} \mathrm{C}$ as coolant temperature. Then by specifying $300^{\circ} \mathrm{C}$ as coolant temperature, the thermal analysis and structural analysis was performed on all the six different blade models and thermal and stress distributions were obtained. The temperature distribution on existing design of turbine blade (with 12 holes) when analyzed with coolant temperature of $300^{\circ} \mathrm{C}$ is much less than that of same blade when analyzed with coolant temperature $500^{\circ} \mathrm{C}$. When the coolant temperature of $300^{\circ} \mathrm{C}$ is intended to be used, it leads to over cooling and affects the performance since an average temperature of $800^{\circ} \mathrm{C}$ is the required allowance blade temperature for the maximum performance of the blade. The temperature distributions for

Table 3: Temperature distribution for different holes

\begin{tabular}{|c|c|}
\hline No. of holes & Temperature distribution $\left({ }^{\circ} \mathbf{C}\right)$ \\
\hline 12 & 679.6 \\
\hline 11 & 707.1 \\
\hline 10 & 755.2 \\
\hline 9 & 784.8 \\
\hline 8 & 792.8 \\
\hline 7 & 827.6 \\
\hline
\end{tabular}

different holes are shown in table 3.

The temperature as obtained when analysed with $300^{\circ} \mathrm{C}$ with coolant temperature against the number of holes is graphically shown in figure 14 . It can clearly see from the graph that when the numbers of holes are increased in the blade, the temperature distribution comes down. Only on the blade configuration with 8 holes, the temperature near to the required temperature i.e., $800^{\circ} \mathrm{C}$ is obtained.

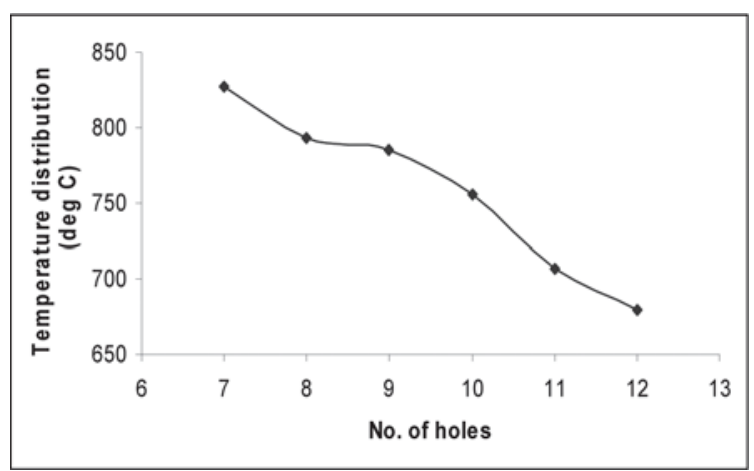

Fig. 14: Temperature distribution Vs Number of holes

For other configuration like blade with 7 holes or blade with 9 holes the temperature distribution is either on a higher side or below the required blade temperature of $800^{\circ} \mathrm{C}$. Since the performance of the turbine will be less if the temperature distribution is either more than or much less than the required blade temperature of $800^{\circ} \mathrm{C}$. The blade with 8 holes is the most optimum number of holes for turbine blade. Graphs shown in figure 15, 16 demonstrate the fact that when the

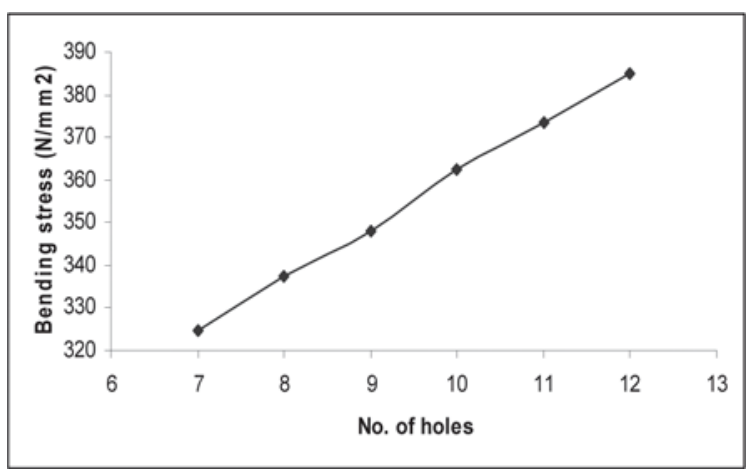

Fig. 15: Bending stress Vs Number of holes 


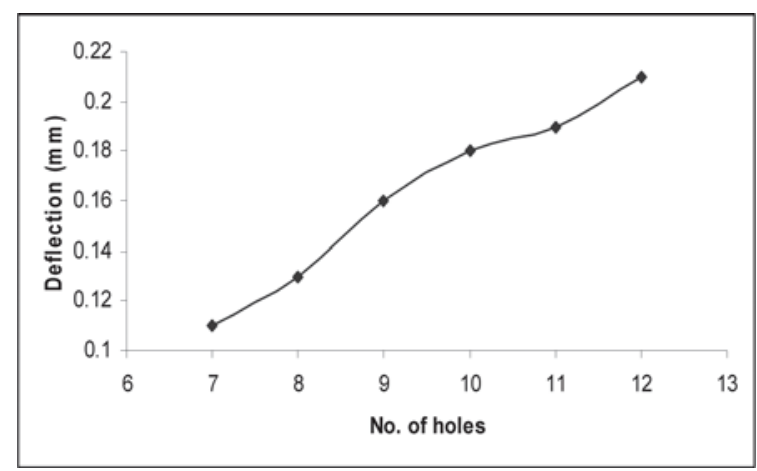

Fig. 16: Deflection Vs Number of holes

holes are more in number, the strength of the blade will be reduced.

Even though the bending stress for blade with 7 holes is less than that of the blade with 8 holes, the temperature distribution is better for blade with 8 holes. This combination of better temperature distribution and lower stress levels in the turbine with 8 numbers of holes makes it as the best possible configuration.

\section{CONCLUSION}

In this paper, using finite element analysis as a tool, the structural and thermal analyses were carried out sequentially. The blade with different no. of holes 7, 8, 9, 10, 11 and 12 were used for analysis. From the results obtained, it was found that the blade with 8 holes has the best temperature distribution when compared other configurations of the blade when the coolant temperature was $300^{\circ} \mathrm{C}$. The temperature distribution for the blade with eight holes, matches closely with prescribed temperature of $800^{\circ} \mathrm{C}$ for the better performance of the turbine. The bending stress, obtained from finite element analysis shows lower stress level for the blade with 8 holes. These results indicate that the blade with eight holes will have optimum performance for the prescribed loading conditions.

\section{REFERENCES}

[1] Gowreesh, S., Sreenivasalu Reddy, N. and Yogananda Murthy, NV. 2009. Convective Heat Transfer Analysis of a Aero Gas Turbine Blade Using Ansys, International Journal of Mechanics and Solids. 4: 39-46.

[2] Facchini, B. and Stecco. S.S. 1999. Cooled expansion in gas turbines: a comparison of analysis methods, Energy Conversion and Management. 40: 1207-1224.

[3] Mohammad, H., Albeirutty., Abdullah, S., Alghamdi., Yousef, S. Najjar. 2004. Heat transfer analysis for a multistage gas turbine using different blade-cooling schemes, Applied Thermal Engineering. 24: 563-577.

[4] Mahfoud, K. and George, B. 1997. Computational study of turbine blade cooling by slot-injection of a gas, Applied Thermal Engineering. 17: 1141-1149.

[5] Moyroud, F., Fransson, T. and Jacquet-Richardet, G. 2002. A comparison of two finite element reduction techniques for mistuned bladed-disks, Journal of Engineering for Gas Turbines and Power. 124: 942-953.

[6] Giovanni, C., Ambra, G., Lorenzo, B. and Roberto, F. 2007 Advances in effusive cooling techniques of gas turbines, Applied Thermal Engineering. 27: 692-698.

[7] Cun-liang, L., Hui-ren, Z., Jiang-tao, B. and Du-chun, X. 2010. Film cooling performance of converging slot-hole rows on a gas turbine blade, International Journal of Heat and Mass Transfer. 53: 5232-5241.

[8] Zhang, JJ., Esat, II. and Shi, YH. 1999. Load Analysis with Varying Mesh Stiffness, Computers and Structures. 70: 273-280.

[9] Hildebrabd, FB. 1997. Introduction to Numerical Analysis, McGraw-Hill, New York.

[10] Moussavi Torshizi, SE., Yadavar Nikravesh, SM. and Jahangiri, A. 2009. Failure analysis of gas turbine generator cooling fan blades, Engineering Failure Analysis. 16: 1686-1695.

[11] Cleeton, JPE., Kavanagh, RM. and Parks, GT. 2009. Blade cooling optimisation in humid-air and steam-injected gas turbines, Applied Thermal Engineering. 29: 3274-3283.

[12] Krishnamoorthy, C. 1994. Finite Element Analysis Theory and Programming, Tata McGraw-Hill, New Delhi.

[13] Martin, HC. and Carey, GF. 2006. Introduction to the Finite Element Analysis, McGraw Hill Publishing Co Ltd, New Delhi. 